\title{
Introduction: Effective Slownesses
}

\section{Distance and Speed in Travelling and Dwelling Throughout Inner Asia}

\author{
Grégory Delaplace and Caroline Humphrey \\ Paris Nanterre University, Nanterre, France \& Mongolia \& Inner Asia Studies \\ Unit, Cambridge, Cambridge, UK \\ gdelaplace@parisnanterre.fr\&ch1ooo1@cam.ac.uk
}

There are probably few problems more universal than that of the variability of speeds at which a given distance might be covered; this applies, arguably, not only to humans and earthly non-humans, but really to any material body in any possible universe. Yet, through one of those curious processes of extreme scalar condensation by which matters of ultra-localised concern come to illuminate matters of very general import (a sort of intellectual operation that social anthropologists have tended to make a speciality of), the papers gathered in this special issue all concur to show how this problem poses itself in a unique way for Inner Asian populations. ${ }^{1}$

Several case studies presented here thus illustrate how strikingly contrasted speeds may be coordinated by a given population within a single system of mobility. Reindeer sledges glide their cargo away through the frozen Siberian tundra, while aircrafts can be seen jolting about up in the air, as they transport a handful of select passengers from one settlement to the other. Horse-relay servicemen wrap up their bellies tightly, so their innards remain in place as they gallop hundreds of miles across the Mongolian steppe and up mountainpasses on a daily basis, while wayfaring camel caravans step measuredly through distant yet well-trodden routes for months on end. There is indeed more than one way in which moving to or through places might be achieved in these areas, and the introduction of motorised land or airborne transport has only added to the possibilities, rarely replacing any pre-existing one.

Yet of course, travels are hardly the only occasions for people to be on the move in Inner Asia, where different brands of nomadic pastoralism involving different mobility patterns have been tried out, abandoned or adopted

1 This special section follows from a conference held in Paris at the Quai Branly-Jacques Chirac Museum on 7 and 8 March 2019. 
throughout history. Dwelling in any portion of land, in this context, precisely involves being able to pace the varying gaits of humans (indeed different kinds of human beings moving at different speeds) with those of other species, domestic or not, which cooperate with herders or stand in competition with them. Things become even trickier when taking into account the perspective of spiritual land masters, known under different names and descriptions throughout the region, but feared everywhere for their ability to mess with people's good fortune when proper distance in regard to them (not too far, not too close) fails to be respected.

Therefore distance, in the context of nomadic herding, is not really an obstacle to be overcome by the application of a certain (and preferably higher) speed, but rather the central concern in anyone's relation to land. When homeland is not only what you travel from or to, but what you circulate within, hoping you will never have to suffer the inconvenience of leaving it, then distance is not really the flipside of dwelling anymore, it becomes constitutive to it. Thus, finding the right distance within a multi-specific — indeed multi-onticland involves finding the right speed of circulation. And what all the papers gathered here seem to be highlighting is that the right speed, throughout Inner Asia, is most often markedly slow. The key finding of this issue, perhaps, at least the conclusion toward which all contributors happen to converge, is that there is a particular concern for slowness across the region, indeed a real passion for it. There almost seems to be a particular brand of slow, specific to Inner Asian livelihoods, a characteristic way of linking deceleration - that is a care taken to move at a slower speed than actually possible - to the effective completion of particular tasks. Or even, one may go as far as saying, to the upholding of a certain ethical stance.

In the opening paper of this issue, Caroline Humphrey parallels two of the most iconic means of distant connection beyond nomadic circuits that Mongolian people have sustained up until the 196os for the purpose of trade, transport and communication: the horse-relay system (örtöö) and camel or yak caravans (jing). These two mobility apparatuses stand in sharp contrast to one another for those involved in them: while horse-riders are made to power through the most fantastic distances every day in order to deliver their messages, putting their own bodies and those of their mounts to a severe test, caravan drivers have the leisure to choose the most appropriate route depending on their duties, on weather conditions, or family obligations; not to mention the resources in 
animals and manpower required to sustain a horse-relay system, compared to the profitability of caravan trading. No wonder the first could only be imposed within a rigid power-structure, while the slowness and 'wayfaring' quality of the second was implemented and felt as an extension of herders' knowledge and practice of an animated land that has to be trodden about diplomatically.

Piers Vitebsky and Anatoly Alexeyev's follow-on describes three styles of movement available to Eveny herders/hunters in Yakutia: the hunting excursion, the seasonal cycle of reindeer herding and the travel to a predetermined destination. 'Why does it matter how fast one goes?' ask the authors-it really is a question of purpose, each endeavour requiring the setting up of a particular pace: one by which hunters may honour the 'rendezvous' they have scheduled with their prey, or one by which the perpetual circuit of nomadisation will take herding families and their animals through a succession of sites, where all kinds of presences will have to be accommodated. Planes and helicopters, in this context, have brought about a speed of teletransportation that verges on science-fiction, within a universe otherwise marked by slow movement to nearby locations.

Vitebsky and Alexeyev's ethnography echoes Tatiana Safonova and Istvan Santha's point, that life in a Siberian village with flight connections to remote settlements and cities feels more distant to its surroundings than in more peripheral rural settlements, where no such air transportation exists. Safonova and Santha's rendition of what it feels like to live in a distant village of Russian, Buryat and Evenki population also borrows from the realm of science-fiction: they liken it to life on a space station, which people cannot really exit from, except when shipped out by an aircraft to their destination. Strangely, while it is always significantly easier to leave the village than to come back to it, some kind of magnetism draws Evenki, Buryat and Russian villagers back every time they have to leave, and even after they cease having actual business there. The state of relative disconnectedness that characterises the village's situation is described by the authors as a regime of 'slow connection', which binds inhabitants together in a common experience of rare local supplies and unpredictable administrative infrastructures.

The challenges posed by having to adjust the contrasted gaits of different animal species into a harmonious rhythm are given a vivid illustration in Alex Oehler's paper: it describes how Soyot communities have transitioned from a reindeer-based pastoralism to one centred around yaks, while the neighbouring Tofa remained reliant on domesticated reindeer for hunting. Actually, each community adopted a different strategy to cope with the diverging paces that herding reindeer and yaks imposed on humans wishing to live and circulate 
alongside them. Implementing 'togetherness' between humans and animals, orchestrating their different 'life worlds', involves getting the range right - that is, finding the distance at which a particular animal species will be able to sustain themselves autonomously while remaining available to human usage. The setting up of this range and its maintenance while moving from one settlement to the next involves attuning to the animal rhythms, and adjusting this to that of other species which constitute the particular milieu of the south Siberian taiga.

Sayana Namsaraeva's article evidences the importance of appropriate speed - that is, of an affected slowness - in relation to what Mongolian people call the nutag, which could be translated as place of origin, dwelling place, national territory or even inhabited land, depending on the context. Approaching one's own nutag should be done slowly, as to any other person's for that matter, out of respect for the living conditions of those who dwell there. Failing to do so inevitably brings about the worst misfortune for its inhabitants, as if 'arrythmia', such as that which is produced by speeding about in one's nutag, could only unsettle the local order on which people's livelihoods depends. Namsaraeva takes as an example for this an ethnic festival in Buryatia where numerous guests hailing from various parts of Russia, China and Mongolia were hosted for a few days. A few problems ended up marring the event, but the least forgivable and the most consequential of all was indeed the haste with which the guests barged into the nutag to which they had been invited.

This finds a striking echo in Laurent Legrain's experience, when he accompanied an old man and his relatives back to the nutag in the far west of Mongolia that he had left in his youth, to go and find fortune in the capital city. To everybody's bemusement, the old man took endless detours around the actual place and people he was scheduled to visit, up until the moment the resources of the travelling party came to dwindle dangerously_-at which point the whole affair found an unexpected and almost magical conclusion. What is most striking in Legrain's account is the way a certain technology of distance, in this case, actually came to be used in order to reduce speed (rather than the other way around, i.e. a technology of speed being used to reduce distance, which is how we usually tend to envision the relationship between these two concepts): as if the most ethical way of coming home, for any wise person, was to stretch the approaching movement by the endless addition of smaller and smaller amounts of distance, in order to bring down the moment of actual arrival to virtual slow motion.

The reason why coming back to one's nutag is such a difficult experience across Mongolian lands, one fraught with risk and uncertainty, probably has to do with the fact that leaving it makes for such a dreaded prospect-one of 
the rare actions that Mongols may not deem it possible to perform really appropriately. Living in exile, as Buryat people still feel they do in Mongolia, or as more and more Mongolian people feel they are doing even within Mongolia, when they leave their rural nutag to come and settle in the capital city, brings about a whole lot of problems that do not always seem to be matched by the prospect of employment and increased wealth that such a move may promise. And yet, young and not-so-young people come and pack into the ger districts in the capital's outskirts, the theme investigated by Bernard Charlier. In the closing paper of this issue, Charlier describes the large and small adaptations made necessary by the near-impossible transposition of one's world from one place to another, as well as the imaginative tactics by which a sense of home may be recreated, or its distant presence brought near, in what seems at first like foreign land. Reading Charlier, it feels as if some distances were indeed impossible to overcome completely, whichever speed might be applied to one's motions through places and space.

\section{Acknowledgements}

The editors wish to thank all the participants of this conference, as well as the Departement de la Recherche et de l'Enseignement at the museum, the Mongolia and Inner Asia Studies Unit at the University of Cambridge and the Institut Universitaire de France for their generous support in the organisation of this event. 